\title{
Oceanography
}

CITATION

Kappel, E.S. 2011. Quarterdeck: Three examples of failure...Or at least they thought so.

Oceanography 24(4):5, http://dx.doi.org/10.5670/oceanog.2011.102.

$\mathrm{DOI}$

http://dx.doi.org/10.5670/oceanog.2011.102

COPYRIGHT

This article has been published in Oceanography, Volume 24, Number 4, a quarterly journal of The Oceanography Society. Copyright 2011 by The Oceanography Society. All rights reserved.

USAGE

Permission is granted to copy this article for use in teaching and research. Republication, systematic reproduction, or collective redistribution of any portion of this article by photocopy machine, reposting, or other means is permitted only with the approval of The Oceanography Society. Send all correspondence to: info@tos.org or The Oceanography Society, PO Box 1931, Rockville, MD 20849-1931, USA. 


\section{Three Examples of Failure... \\ Or at Least They Thought So}

Three women in their fifties who received their doctoral degrees from the same oceanographic institution within a few years of each other recently reunited at a conference. One is a leading researcher, one is the CEO of a scientific company, and the other is president of a small business specializing in geoscience communication. They hadn't been together for nearly 20 years, and understandably spent some time catching up on their careers, with a peppering of family. As the conversation progressed, first one, then the other, then the third announced that earlier in her career, she had felt she was a failure. The researcher had thought that she was a failure because she never earned the title of professor. The CEO had thought that she was a failure because she left the geosciences. The small business owner had thought that she was a failure because she left research.

By most objective measures, these three women have had successful careers. How could it be that they all had felt like failures? There are no data to suggest that this sense of failure is unique to women or that this particular oceanographic institution fails to properly mentor its students, male and female. It's unclear how pervasive this feeling of failure is among young ocean science $\mathrm{PhDs}$ who are not professors, but it is hard to imagine that any of their mentors ever sensed these women's feelings of failure at the time. Importantly, those mentors undoubtedly now look at these past students as very successful peers in a complex world.
The real point here is that success in the sciences can take on more forms than young scientists with little life experience can anticipate. Maturity can possibly be characterized as the ability to define your own successand it only comes with experience. These three women are excellent role models. They all consciously pursued career paths that were best suited to their skills, personalities, and personal circumstances. Their work-and the larger scientific community-has benefited from their rigorous doctoral training, even if none if them is addressed as "professor." Their work is challenging and intellectually stimulating. The job opportunities they have had over the course of theirs careers were, in large part, due to the intellectual foundations and research networks they started building during graduate school.

It is critical that oceanographic institutions embrace and mentor their graduates, often the majority, who seek or end up in careers outside of academia. We need to stop using the ever-so-slightly disparaging term "alternate career" to describe the array of important pathways taken by this group, for our society needs scientifically trained minds working on all facets of our future. (See Oceanography's "Career Profiles" section for some good examples.) The next generation of students who follow the diverse paths that these women followed should be treated like-and should feel like-successes.

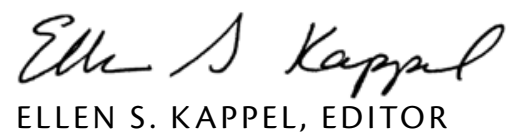

